[Supporting Information]

\title{
Synthesis, Characterization, and Functionalization of Hyperbranched Poly(3,4-epoxycyclohexanemethanol)
}

\author{
Yoshikazu Kitajyo, ${ }^{\dagger}$ Yuki Kinugawa, ${ }^{\dagger}$ Masaki Tamaki, ${ }^{\dagger}$ Harumi Kaga,${ }^{\dagger}$ Noriaki Kaneko, ${ }^{\S}$ \\ Toshifumi Satoh, ${ }^{* \perp}{ }^{*}$ and Toyoji Kakuchi ${ }^{*}$
}

${ }^{\dagger}$ Division of Biotechnology and Macromolecular Chemistry, Graduate School of Engineering, Hokkaido University, Sapporo 060-8628, Japan; ${ }^{*}$ National Institute of Advanced Industrial Science and Technology (AIST), 2-17-2-1 Tsukisamu-Higashi, Toyohira-ku, Sapporo 062-8517, Japan; ${ }^{\S}$ MACROTEC Co., 2-17-2-1 Tsukisamu-Higashi, Toyohira-ku, Sapporo 062-8517, Japan; ${ }^{\perp}$ Division of Innovative Research, Creative Research Initiative "Sousei" (CRIS), Hokkaido University, Sapporo 001-0021, Japan

\section{Contents.}

1. The detailed peak assignments of poly-1, $\mathbf{4 a} / \mathbf{4 b}$, and $\mathbf{5 a} / \mathbf{5 b}$.

(Pages 2 - 3)

2. Calculation of the degrees of substitution (DSs) and the calculated molecular weights $\left(M_{\mathrm{w}, \mathrm{cal}}\right)$ of carbamate derivative of poly-1.

(Pages 4 - 5)

2. Calculation of the degrees of substitution (DSs) and the calculated molecular weights $\left(M_{\mathrm{w}, \mathrm{cal}}\right)$ of poly-1ASP.

3. Calculation of the degrees of substitution (DSs) and the calculated molecular weights $\left(M_{\mathrm{w}, \mathrm{cal}}\right)$ of poly-3ASP. 
1. The detailed peak assignments of poly-1, $\mathbf{4 a} / \mathbf{4 b}$, and $\mathbf{5 a} / \mathbf{5 b}$.

(a)
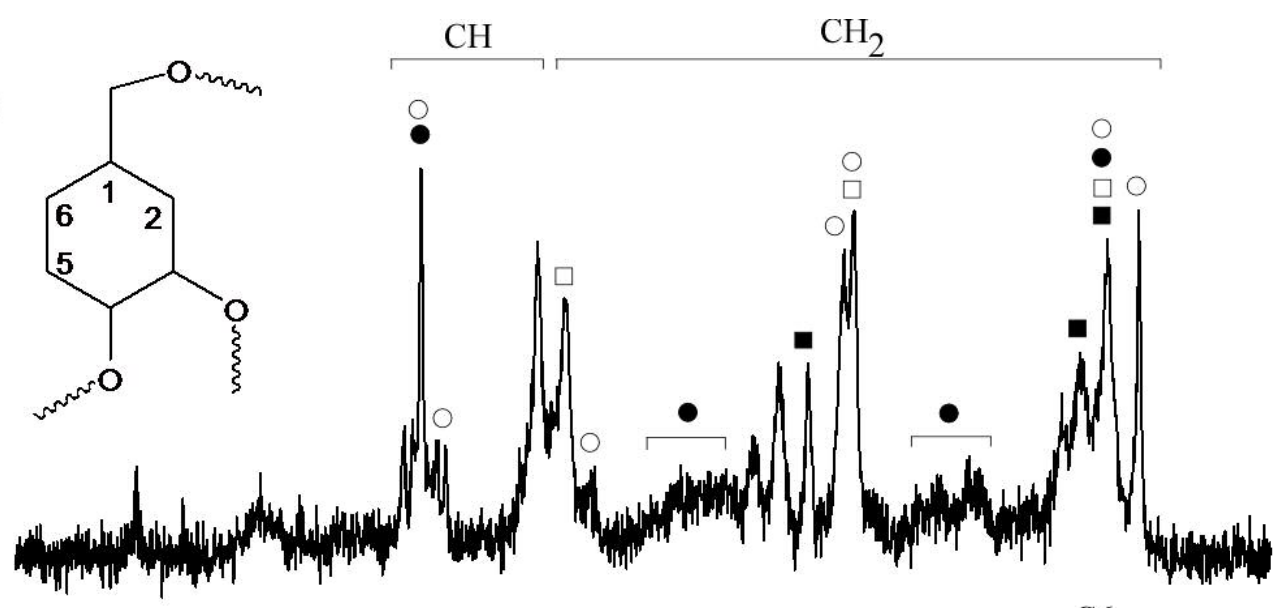

(b)
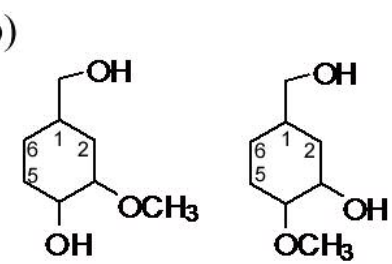

C1

$4 a$

4b

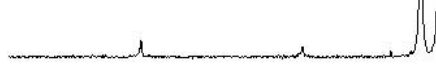

C2

C6

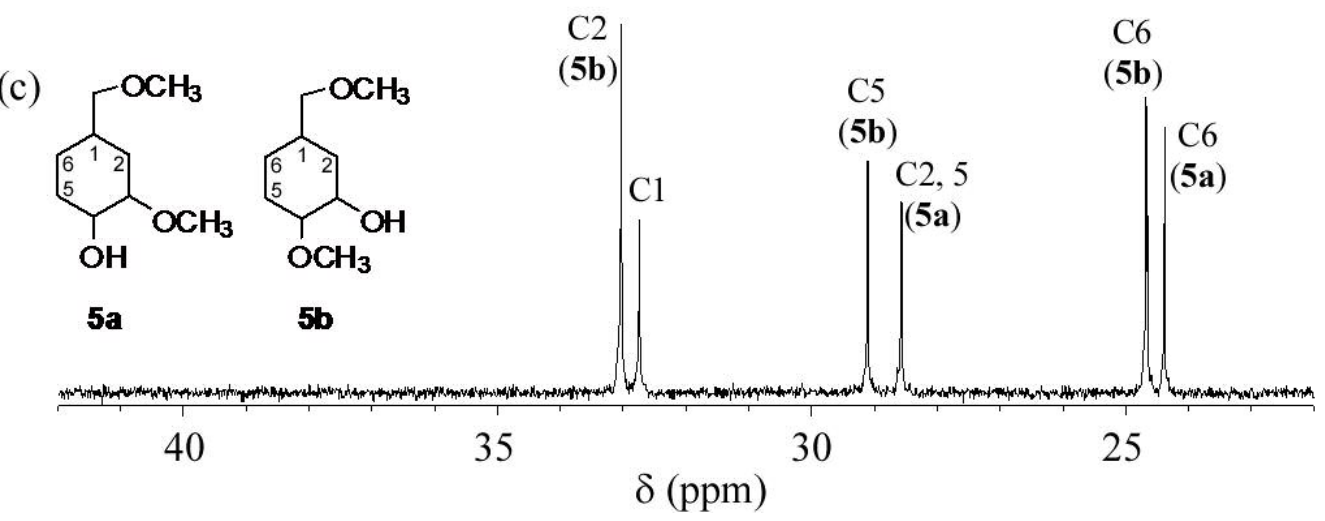

Figure S1. Expanded ${ }^{13} \mathrm{C}$ NMR spectra of (a) poly-1 (open circle, $\boldsymbol{T}_{\mathbf{a}}$ and $\boldsymbol{T}_{\mathbf{b}}$; closed circle, $\boldsymbol{L}_{\mathbf{a}}$; open square, $\boldsymbol{L}_{\mathbf{b}}$; closed square, $\left.\boldsymbol{D}\right)$, (b) $\mathbf{4 a} / \mathbf{4 b}$, and (c) $\mathbf{5 a} / \mathbf{5 b}$ in $\mathrm{CD}_{3} \mathrm{OD}$. 
Table S1. ${ }^{13} \mathrm{C}$ chemical shifts $(\delta / \mathrm{ppm})$ of the model compounds in $\mathrm{CD}_{3} \mathrm{OD}^{a}$

\begin{tabular}{|c|c|c|c|c|c|c|c|}
\hline carbons & poly-1 & $4 \mathbf{a}(\circ)^{b}$ & $\mathbf{4 b}(\circ)^{b}$ & poly-3 $(\bullet)^{b}$ & $5 \mathbf{a}(\square)^{b}$ & $\mathbf{5 b}(\square)^{b}$ & $6(\square)^{b}$ \\
\hline \multirow[t]{3}{*}{$\mathrm{C} 1(\mathrm{CH})$} & $35.47\left(T_{\mathrm{a}}, L_{\mathrm{a}}\right)$ & 35.45 & & 35.54 & & & \\
\hline & $35.07\left(\boldsymbol{T}_{\mathbf{b}}\right)$ & & 35.16 & & & & \\
\hline & & & & & 32.76 & 32.76 & 32.68 \\
\hline \multirow[t]{5}{*}{$\mathrm{C} 2\left(\mathrm{CH}_{2}\right)$} & $33.17\left(\boldsymbol{L}_{\mathrm{b}}\right)$ & & & & & 33.04 & \\
\hline & $32.78\left(\boldsymbol{T}_{\mathbf{b}}\right)$ & & 32.78 & & & & \\
\hline & $32.23-30.39\left(\boldsymbol{L}_{\mathbf{a}}\right)$ & & & $31.13-30.91$ & & & \\
\hline & $29.33(\boldsymbol{D})$ & & & & & & 29.23 \\
\hline & $28.75\left(\boldsymbol{T}_{\mathrm{a}}\right)$ & 28.82 & & & & & \\
\hline
\end{tabular}

28.57

$\mathrm{C} 5\left(\mathrm{CH}_{2}\right) \quad 28.61\left(\boldsymbol{T}_{\mathrm{a}}, \boldsymbol{L}_{\mathbf{b}}\right) \quad 28.53$

$27.76-26.31\left(\boldsymbol{L}_{\mathbf{a}}\right)$
24.60

$27.16-26.77$
28.57

$29.11 \quad 24.31$

$24.98(D)$

$24.57\left(\boldsymbol{T}_{\mathbf{b}}, \boldsymbol{L}_{\mathbf{a}}, \boldsymbol{L}_{\mathbf{b}}\right)$

$24.07\left(\boldsymbol{T}_{\mathrm{a}}\right)$

24.09

\footnotetext{
${ }^{a}$ Solvent peak $(\delta=49.00 \mathrm{ppm})$ was used as the internal reference. ${ }^{b} \circ$, peaks corresponding to terminal units $\left(\boldsymbol{T}_{\mathbf{a}}\right.$ and $\left.\boldsymbol{T}_{\mathbf{b}}\right) ; \bullet$, peaks corresponding to 3,4-linked linear unit $\left(\boldsymbol{L}_{\mathbf{a}}\right)$; $\square$, peaks corresponding to 1,3-linked and 1,4-linked linear units $\left(\boldsymbol{L}_{\mathbf{b}}\right) ; \mathbf{\square}$, peaks corresponding to dendritic unit $(\boldsymbol{D})$.
} 
2. Calculation of the degrees of substitution (DS) value and the molecular weight value of the carbamate derivative of poly-1 $\left(M_{\mathrm{w}, \mathrm{cal}}\right)$.

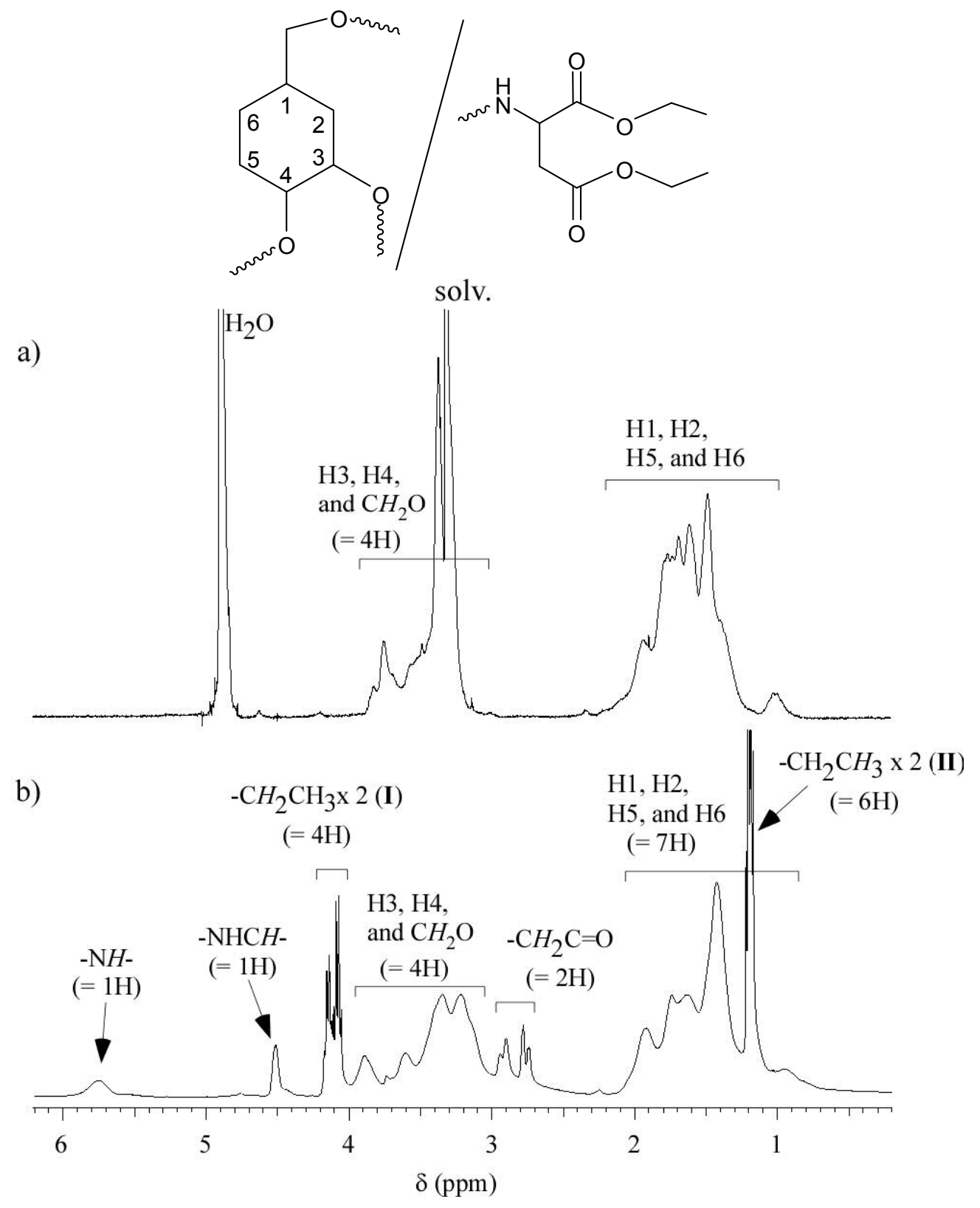

Figure S2. $\quad{ }^{1} \mathrm{H}$ NMR spectra of (a) poly-1 in $\mathrm{CD}_{3} \mathrm{OD}$ and (b) carbamate derivative of poly-1 in $\mathrm{CDCl}_{3}$.

The degree of substitution (DS) value of the obtained polymer was estimated using eq.S1.

$\mathrm{DS}=\frac{\text { relative content of substituent }}{\text { relative content of monomer unit in poly }-1} \times 100(\%)$ 
The relative content of substituent was calculated from the peak area of the signals at $4.20-4.02$ ppm due to methylene proton in ethyl group $(\mathbf{I}, 4 \mathrm{H})$.

relative content of substituent $=\frac{\mathbf{I}}{4}=0.888$

The relative content of monomer unit in poly-1 was also calculated from the peak area, which is the subtracted value the peak area of methyl proton in ethyl group $(\mathbf{I I}=\mathbf{I} \times 1.5)$ from that of the signals at $2.10-$ $0.72 \mathrm{ppm}$.

relative content of monomer unit $=\frac{(\text { peak area of the signals at } 2.10-0.72 \mathrm{ppm})-\mathbf{I} \times 1.5}{7}=3.998$

Therefore, the DS value of the obtained polymer was $22 \%$. The molecular weight of the obtained polymer $\left(M_{\mathrm{w}, \mathrm{cal}}\right)$ was 14,100 , which was estimated by eq.S2.

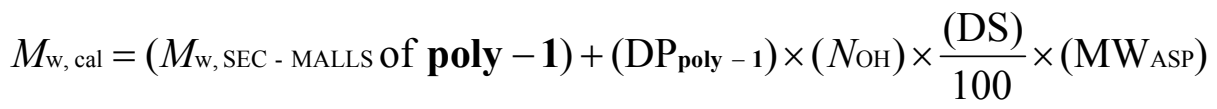

$\mathrm{DP}_{\text {poly-1 }}:$ degree of polymerization of poly-1 $=\left(M_{\mathrm{w}, \mathrm{SEC}-\mathrm{MALLS}}\right) / 128.17=80.4$

$N_{\mathrm{OH}}$ : average number of $\mathrm{OH}$ groups per monomer unit in poly-1 $=1$

$\mathrm{MW}_{\text {ASP }}$ : molecular weight of $N$-carbonyl L-aspartic acid diethyl ester $=215.2$ 
3. Calculation of the DS and $M_{\mathrm{w}, \mathrm{cal}}$ values of poly-1ASP.

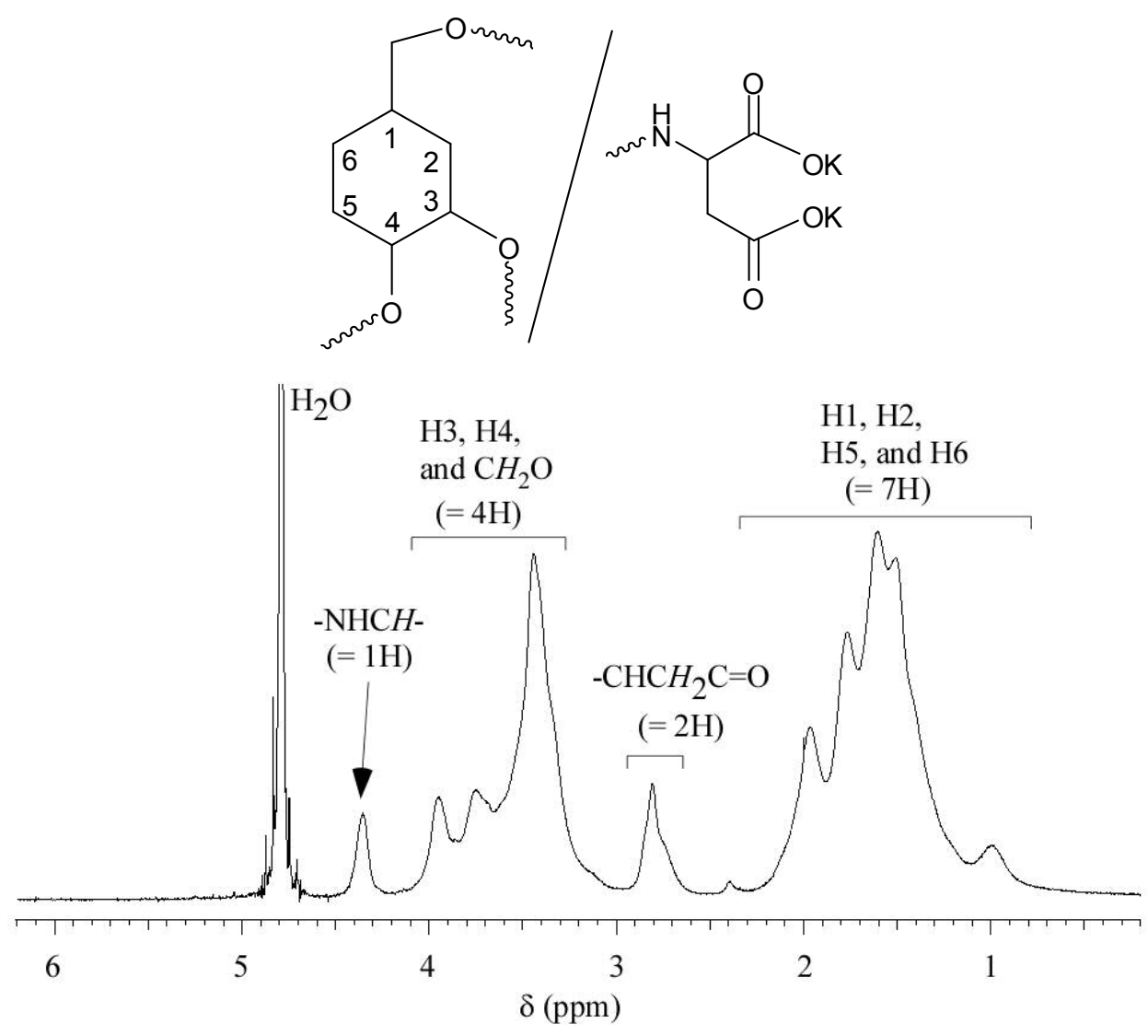

Figure S3. ${ }^{1} \mathrm{H}$ NMR spectrum of poly-1ASP in $\mathrm{D}_{2} \mathrm{O}$.

The DS value of poly-1ASP was $22 \%$, estimated by the following equation (eq.S3).

$$
\begin{aligned}
\mathrm{DS} & =\frac{\text { relative content of substituent }}{\text { relative content of monomer unit in poly }-\mathbf{1}} \times 100(\%) \\
& =\frac{(\text { peak area of the signal at } 2.80 \mathrm{ppm}) / 2}{(\text { peak area of the signals at } 2.43-0.82 \mathrm{ppm}) / 7} \times 100
\end{aligned}
$$

$M_{\mathrm{w}, \mathrm{cal}}$ of poly-1ASP was 14,500, which was estimated by eq.4.

$M_{\mathrm{w}, \mathrm{cal}}=\left(M_{\mathrm{w}, \mathrm{SEC}-\mathrm{MALLS}}\right.$ of poly $\left.-\mathbf{1}\right)+\left(\mathrm{DP}_{\mathbf{p o l y}}-\mathbf{1}\right) \times\left(N_{\mathrm{OH}}\right) \times \frac{(\mathrm{DS})}{100} \times\left(\mathrm{MW}_{\mathrm{ASPK}}\right)$

$\mathrm{MW}_{\mathrm{ASPK}}$ : molecular weight of $N$-carbonyl L-aspartic acid potassium salt $=235.3$ 
4. Calculation of the DS and $M_{\mathrm{w}, \mathrm{cal}}$ values of poly-3ASP.

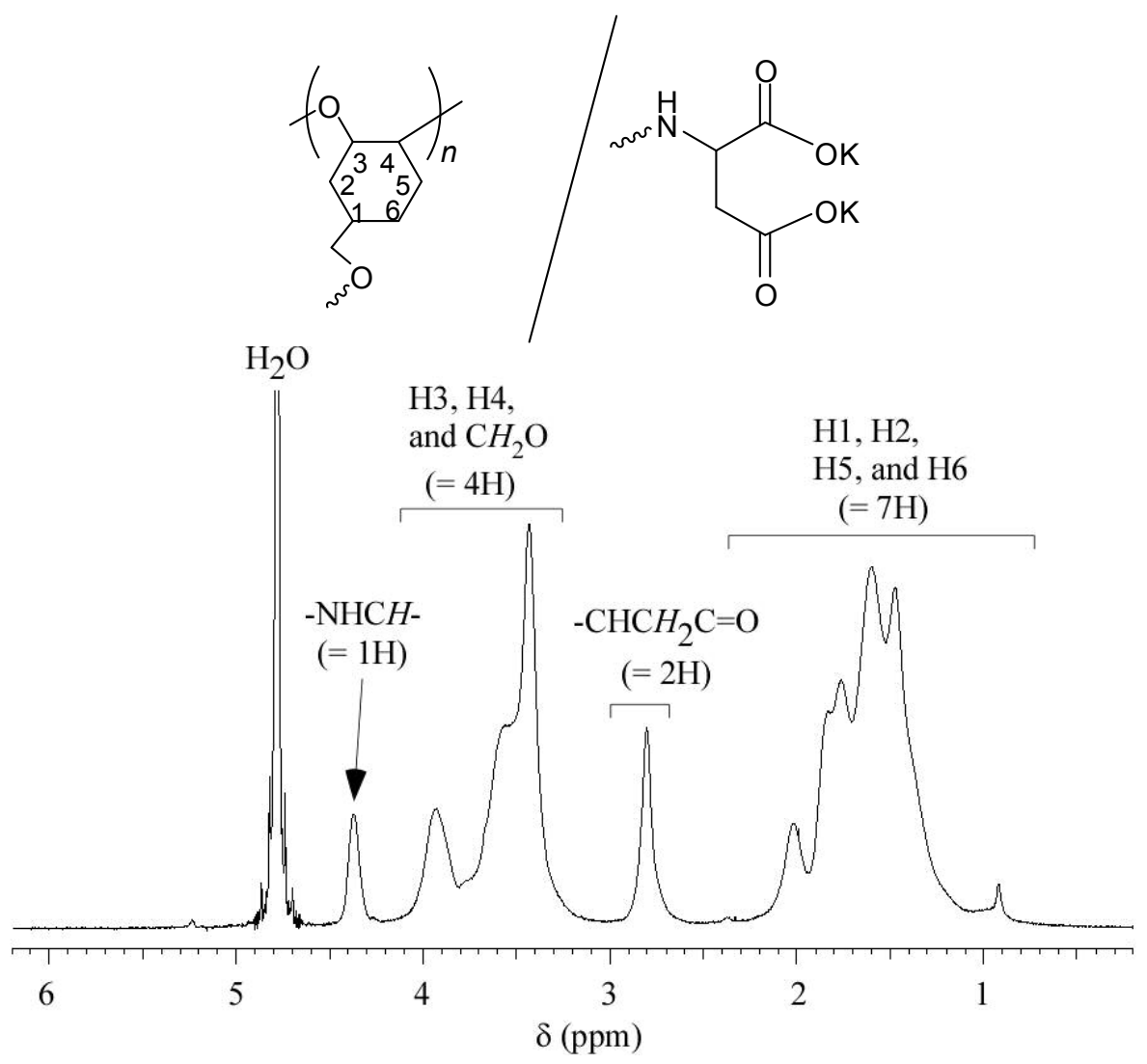

Figure S4. ${ }^{1} \mathrm{H}$ NMR spectrum of poly-3ASP in $\mathrm{D}_{2} \mathrm{O}$.

The DS value of poly-3ASP was $31 \%$, estimated by the following equation (eq.S5).

$$
\begin{aligned}
\mathrm{DS} & =\frac{\text { relative content of substituent }}{\text { relative content of monomer unit in poly }-\mathbf{3}} \times 100(\%) \\
& =\frac{(\text { peak area of the signal at } 2.80 \mathrm{ppm}) / 2}{(\text { peak area of the signals at } 2.43-0.86 \mathrm{ppm}) / 7} \times 100
\end{aligned}
$$

$M_{\mathrm{w}, \mathrm{cal}}$ of poly-3ASP was 25,100, which was estimated by eq.S6.

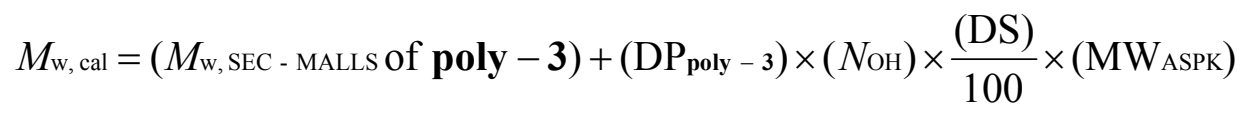

$\mathrm{DP}_{\text {poly-3 }}:$ degree of polymerization of poly-3 $=\left(M_{\mathrm{w}, \mathrm{SEC}-\mathrm{MALLS}}\right) / 128.17=124.8$

$\mathrm{MW}_{\mathrm{ASPK}}$ : molecular weight of $N$-carbonyl L-aspartic acid potassium salt $=235.3$ 